\title{
EVALUATION OF ESCHERICHIA COLI O157:H7 TRANSLOCATION AND DECONTAMINATION FOR BEEF VACUUM-PACKAGED SUBPRIMALS DESTINED FOR NON-INTACT USE
}

\author{
A Thesis \\ by \\ JACOB LYNN LEMMONS
}

\begin{abstract}
Submitted to the Office of Graduate Studies of
Texas A\&M University

in partial fulfillment of the requirements for the degree of

MASTER OF SCIENCE
\end{abstract}

May 2011

Major Subject: Animal Science 


\title{
EVALUATION OF ESCHERICHIA COLI O157:H7 TRANSLOCATION AND DECONTAMINATION FOR BEEF VACUUM-PACKAGED SUBPRIMALS \\ DESTINED FOR NON-INTACT USE
}

\author{
A Thesis \\ by \\ JACOB LYNN LEMMONS
}

\begin{abstract}
Submitted to the Office of Graduate Studies of
Texas A\&M University

in partial fulfillment of the requirements for the degree of

MASTER OF SCIENCE
\end{abstract}

Approved by:

Co-Chairs of Committee, Jeffrey W. Savell

Kerri B. Harris

Committee Member, R. Daniel Lineberger

Head of Department, H. Russell Cross

May 2011

Major Subject: Animal Science 


\begin{abstract}
Evaluation of Escherichia coli O157:H7 Translocation and Decontamination for Beef Vacuum-Packaged Subprimals Destined for Non-Intact Use. (May 2011) Jacob Lynn Lemmons, B.S., Texas A\&M University Co-Chairs of Advisory Committee: Dr. Jeffrey W. Savell Dr. Kerri B. Harris
\end{abstract}

The translocation of Escherichia coli $\mathrm{O} 157: \mathrm{H} 7$ as well as the impact of water washing and partial or complete surface trimming as possible pathogen reduction strategies were evaluated for vacuum-packaged beef subprimals destined for non-intact use. Cap-on and cap-off beef top sirloin butts were inoculated with two levels of E. coli O157:H7- a high-inoculum at approximately $10^{4} \mathrm{CFU} / \mathrm{cm}^{2}$ and a low-inoculum at approximately $10^{2} \mathrm{CFU} / \mathrm{cm}^{2}$. Following inoculation, the subprimals were vacuum packaged and stored for either 0,14 , or 28 days. Upon opening, the following sites were evaluated: exterior of the bag, purge, the inoculation site on the subprimal, the area adjacent to the inoculation site, and the surface opposite from the inoculation site. The following treatments then were applied: water wash, water wash followed by full-surface trimming, water wash followed by partial-surface trimming, full-surface trimming, fullsurface trimming followed by water wash, partial-surface trimming, and partial-surface trimming followed by water wash.

For both high and low inoculated top sirloin butts, contamination of adjacent and opposite surfaces was found after vacuum packaging. Of the treatments applied, water 
washing alone and partial-surface trimming were the least effective for both high and low inoculated subprimals. Full trimming, with or without a water wash, proved to be the most effective treatment used to reduce $E$. coli $\mathrm{O} 157: \mathrm{H} 7$ to non-detectable levels. 


\section{DEDICATION}

I dedicate this work to my friends and family. Without their support, none of this would have been possible. 


\section{ACKNOWLEDGEMENTS}

This project was funded partially by The Beef Checkoff as part of their ongoing mission to increase beef safety.

I thank my committee co-chairs, Drs. Savell and Harris, for allowing me this opportunity to further my education in meat science and food safety. I also thank Dr. Dan Lineberger for being a member of my committee. In addition, I thank Lisa Lucia for her countless hours of assistance throughout this study.

Completing this study would not have been possible without the hard work and dedication of my fellow graduate students: Brittany Laster, Ashley Haneklaus, John Arnold, Miles Guelker, Laura May, and Scott Langley. I also thank the undergraduate student workers: Haley Grimes, Kayla Nelson, Julianne Riley, Katie Stephens, Kelly Thompson, Scott Winkler, and Trace Booth.

I also thank the microbiology graduate students for all of their assistance in the laboratory: Mary Pia Cuervo, Mariana Villarreal, Sujitta Raungrusmee, Megha Adavi, Keila Perez, Amanda King, and Holly Edwards. 
TABLE OF CONTENTS

Page

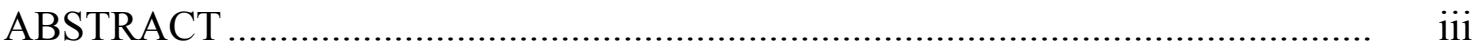

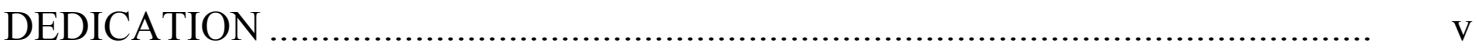

ACKNOWLEDGEMENTS …………………………................................... vi

TABLE OF CONTENTS …........................................................................... vii

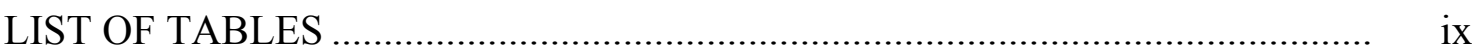

CHAPTER

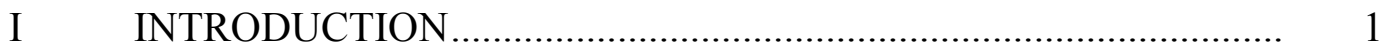

II LITERATURE REVIEW ......................................................

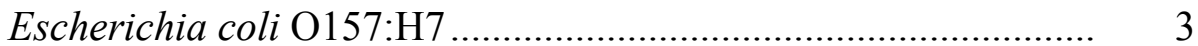

Non-Intact Beef ...................................................................... 8

Pre-Harvest Interventions.............................................................. 9

Hide-On Decontamination ........................................................... 10

Harvest Interventions .......................................................... 11

Fabrication Interventions........................................................ 15

III MATERIALS AND METHODS ……………................................. 16

Product Preparation and Treatments .............................................. 16

Bacterial Cultures and Inoculum Preparation ............................... 17

Subprimal Inoculation ............................................................. 18

Sample Collection .................................................................... 19

Microbiological Examination....................................................... 20

Statistical Analysis ................................................................ 21

IV RESULTS AND DISCUSSION ..................................................... 22 
CHAPTER Page

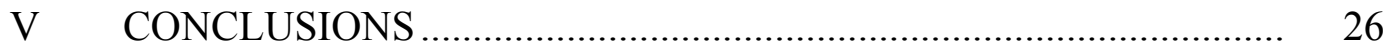

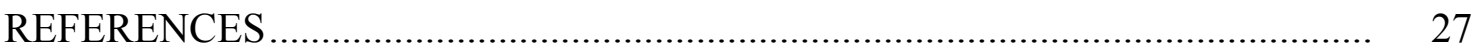

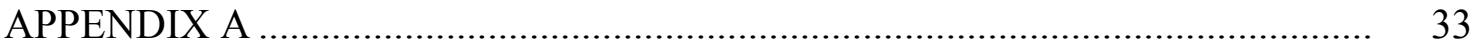

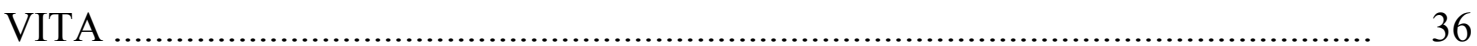




\section{LIST OF TABLES}

Page

Table 1 Least squares means for storage day $\times$ cap $\times$ treatment effect on counts $\left(\log _{10} \mathrm{CFU} / \mathrm{cm}^{2}\right)$ of $E$. coli $\mathrm{O} 157: \mathrm{H} 7$ at the inoculation site or inoculated side of top sirloin butts

Table 2 Least squares means for storage day $\times$ cap $\times$ treatment effect on counts $\left(\log _{10} \mathrm{CFU} / \mathrm{cm}^{2}\right)$ of E. coli $\mathrm{O} 157: \mathrm{H} 7$ at the adjacent site or inoculated side of top sirloin butts

Table 3 Least squares means for storage day $\times$ cap $\times$ treatment effect on counts $(\log 10 \mathrm{CFU} / \mathrm{cm} 2)$ of $E$. coli $\mathrm{O} 157: \mathrm{H} 7$ at the opposite side of top sirloin butts 


\section{CHAPTER I}

\section{INTRODUCTION}

Food safety continues to be a major focus of the beef industry, and the pressure being placed on establishments by the United States Department of Agriculture's Food Safety and Inspection Service (USDA-FSIS) to support their food safety decisions has increased tremendously. An increased number of positive test results and illnesses associated with E. coli $\mathrm{O} 157: \mathrm{H} 7$ from beef in recent years has led to many recalls of beef products $(29,39)$. Consequently, the beef industry has been questioned and often criticized by both consumers and USDA-FSIS. Therefore, industry food safety practices, specifically those for E. coli $\mathrm{O} 157: \mathrm{H} 7$, are under increased scrutiny.

Ensuring safe beef products for the consumer should be the ultimate goal of any processor, and establishments have designed and implemented food safety systems to address specific pathogens of concern. A large percentage of the research for reducing pathogen contamination has focused on treating the carcasses during harvest and upon entering fabrication $(3,4,22)$. The use of water washing and surface trimming to remove visible contamination from beef carcasses has been studied extensively. The application of a water washing intervention to decontaminate beef carcasses has been

This thesis follows the style of Journal of Food Protection. 
shown to reduce $E$. coli $\mathrm{O} 157: \mathrm{H} 7$ contamination (7); however, these reductions were less effective than other interventions $(6,20)$. Additionally, the application of a water wash can spread E. coli O157:H7 beyond the original contaminated area $(17,20)$. Surface trimming has been more effective in removing E. coli $\mathrm{O} 157: \mathrm{H} 7$ and has been shown to spread less contamination than water washing (20). However, research addressing interventions that can be applied to subprimals has shown that interventions that are effective on hot carcass surfaces may not be as successful on chilled subprimal surfaces (1).

Further processing establishments often use boxed, vacuum-packaged subprimals to produce tenderized beef steaks and roasts. Although previous research has shown that the prevalence of E. coli $\mathrm{O} 157: \mathrm{H} 7$ on beef subprimals is low (24), there is a possibility that the exterior surfaces of the subprimals could be contaminated with this microorganism. If the exterior surface of a subprimal is contaminated with E. coli O157:H7, blade tenderization or needle injection can internalize the pathogen (28). Moreover, it is imperative to understand how contamination can spread while the subprimal is vacuum packaged in order to adequately remove E. coli $\mathrm{O} 157: \mathrm{H} 7$ from all contaminated surfaces of chilled subprimals prior to tenderization or injection.

Therefore, this study investigated the potential of translocation of E. coli O157:H7 from one area on the surface of chilled, vacuum-packaged beef subprimals to other areas on the subprimal surface and the use of water wash and surface trimming to decontaminate subprimals that could be used to produce non-intact products. 


\section{CHAPTER II \\ LITERATURE REVIEW}

There are an estimated 47.8 million cases of food borne illness in the United States annually, with 127,839 hospitalizations and 3,037 deaths (12). Known food borne pathogens account for 9.4 million cases of illness, while 38.4 million cases are the result of unspecified agents (12).

\section{Escherichia coli 0157:H7}

Escherichia coli $\mathrm{O} 157: \mathrm{H7}$ causes an estimated 96,534 illnesses, 3,268

hospitalizations and 31 deaths per year (33). The public health costs of E. coli O157:H7 reach $\$ 989$ million per year with a 10 -year cost of $\$ 2.67$ billion (26).

History. The Escherichia genus was named for Theodor Escherich, who isolated the organism from feces in 1885 (13). Outbreaks associated with E. coli date back to the 1940s, when the H7 serotype was first isolated (2). In 1955, hemolytic uremic syndrome was recognized as a symptom associated with illness caused by E. coli (2). Food borne illness caused by E. coli was first reported in 1971 when $E$. coli was implicated in an outbreak associated with imported cheese (2). In 1982, E. coli O157:H7 was recognized as a cause of human illness (17). Outbreaks of E. coli O157:H7 have been reported in beef, cheese, sprouts, salami, and apple cider (2). The most well-known outbreak of $E$. coli $\mathrm{O} 157: \mathrm{H} 7$ occurred in 1993, when this organism caused 700 illnesses and 4 deaths in the Pacific Northwest (17). 
Characteristics. E. coli is a member of the Enterobacteriaceae family $(2,13$, 35). E. coli cells are typically 1.1 to $1.5 \mu \mathrm{m}$ wide by 2 to $6 \mu \mathrm{m}$ long and occur as single, straight rods (13). E. coli are motile; peritrichous flagella give E. coli its mobility and are also part of the serology of the organism $(2,35)$. E. coli is classified as a coliform, which indicates that it a Gram-negative non-sporeforming rod that can ferment lactose within 48 hours (2).

E. coli $\mathrm{O} 157: \mathrm{H} 7$ produces a potent cytotoxin similar to toxins produced by Shigella $(17,23)$. E. coli $\mathrm{O} 157: \mathrm{H} 7$ gained the ability to produce these toxins through a bacteriophage that transferred genes from Shigella to E. coli (17). These Shiga toxins can cause severe damage to the intestinal lining and possibly the internal organs of the host $(15,27)$.

Growth and Survival. E. coli $\mathrm{O} 157: \mathrm{H} 7$ can grow and survive in the gastrointestinal tract of many species; however, cattle are the primary reservoir and shed the bacteria in their feces (17). Infections are spread primarily through ingestion of foods from animal origin, with raw or undercooked beef as the most common source for the infection $(17,31)$. The survival and growth of this organism in food are greatly impacted by temperature, water activity, and $\mathrm{pH}$ (17).

E. coli $\mathrm{O} 157: \mathrm{H} 7$ is more heat sensitive than other Gram-negative bacteria; its optimum growth temperature is $37^{\circ} \mathrm{C}$, and it will not grow below $8^{\circ} \mathrm{C}$ or above $45^{\circ} \mathrm{C}$ (17). However, this serotype survives freezing $(17,31)$. 
E. coli O157:H7 has an unusual tolerance to dryness. In 1994, an outbreak of $E$. coli $\mathrm{O} 157: \mathrm{H} 7$ was caused by dry-cured salami (31). A study of processed salami revealed that the pathogen could survive at a water activity of 0.90 for 32 days (31).

E. coli $\mathrm{O} 157: \mathrm{H} 7$ tends to be tolerant of acids. This pathogen has been documented in acidic foods, including fermented sausages $(17,18,31)$. In 1991, 23 cases of $E$. coli $\mathrm{O} 157: \mathrm{H} 7$ were reported in Massachusetts after consumption of contaminated apple cider (31). E. coli $\mathrm{O} 157: \mathrm{H} 7$ has also been found to be more resistant to organic acid sprays used as pathogen interventions than Listeria monocytogenes and Salmonella Typhimurium (20). Acidic conditions of foods and the acidity of gastric juice in the stomach are important barriers to infection caused by pathogens $(17,31)$. As a result of the acid tolerance displayed by E. coli $\mathrm{O} 157: \mathrm{H} 7$, the pathogen can survive the acidity of the stomach and can reach the gastrointestinal tract with a lower population than some other pathogens, which may explain why this serotype is infectious at a low dose (31).

Serology. Serology is a useful tool for distinguishing strains of E. coli, and it is used in tracking clinical isolates back to their food sources in food borne disease outbreaks (2). Serotyping is based on three antigens: $\mathrm{O}, \mathrm{K}$, and $\mathrm{H}$. The $\mathrm{O}$ antigen is associated with the outer membrane, the $\mathrm{K}$ antigen is associated with the cell capsule, and the $\mathrm{H}$ antigens are part of the flagella. The $\mathrm{K}$ antigen is not used in most typing schemes, only the $\mathrm{O}$ and $\mathrm{H}$ antigens are commonly employed (2).

Virulence. E. coli can also be classified according to virulence factors that are directly associated with the intestinal disease process (35). The characteristics used for 
the virotyping system include patterns of bacterial attachment on host cells, production of toxins, and invasiveness (35).

Enteroaggregative E. coli (EAEC) adhere to cultured cells and are associated with both acute and persistent diarrhea that can last as long as 14 days (2). The mechanisms of pathogenesis as well as the epidemiology of this group is poorly understood (13). Some strains of this group can produce a heat-stable enterotoxin (2).

Enteropathogenic E. coli (EPEC) are similar to EAEC in that they adhere to the cells of the intestinal mucosa (2). This group of E. coli is a major cause of acute or chronic enteritis in children in developing countries (13). The clinical symptoms associated with EPEC include electrolyte loss and epithelial damage (13). Although these strains can cause diarrhea, they do not produce enterotoxins (2).

Enterotoxigenic E. coli (ETEC) were among the first to be recognized as a group due to their association with traveler's diarrhea $(2,13)$. This group produces heat-labile and heat-stable enterotoxins $(2,13)$. Symptoms of ETEC include acute watery diarrhea without fever that may be mild and of short duration but in some cases can be similar to cholera $(2,13)$.

Enteroinvasive E. coli (EIEC) can cause severe disease and can spread between cells in a manner similar to Shigella (2). They invade the host intestinal epithelial cells and multiply, causing cell destruction and an inflammatory response (13). Symptoms include watery diarrhea prior to the onset of dysentery with some stools containing blood and mucus, as well as headache, fever, and cramping (13). EIEC outbreaks are usually 
associated with water, food contaminated by human feces or person-to-person transmission; however, the incidence of disease in developed countries is low (13). Enterohemorrhagic E. coli (EHEC) have the ability to produce enterotoxins similar to the Shiga toxin produced by Shigella dysenteriae (13). Symptoms of EHEC range from mild diarrhea to hemorrhagic colitis and hemolytic uremic syndrome (13). This group is associated with a wide variety of foods, including beef, water, vegetables, and apple cider (2). There are many serotypes of EHEC, including E. coli O157:H7 as well as other notorious strains such as $\mathrm{O} 111$ and $\mathrm{O} 26$ (13).

Clinical Illness. E. coli $\mathrm{O} 157: \mathrm{H} 7$ has a low infectious dose in humans, requiring the ingestion of less than 50 organisms to cause disease (15). Infection of E. coli O157:H7 begins with mild diarrhea, abdominal cramps, and fever; this can soon escalate to bloody diarrhea and severe abdominal pain (17). Complications from infection can lead principally to three life-threatening human illnesses: hemorrhagic colitis (HC), hemolytic uremic syndrome (HUS), and thrombotic thrombocytopenic purpura (TTP) $(17,24,31,32)$.

$\mathrm{HC}$ is characterized by sudden abdominal pain, followed by the onset of diarrhea within $24 \mathrm{~h}$ with bloody diarrhea within several days (31). HC is typically absent of a fever, but when fever does occur it is low grade (31). The incubation period ranges from 3 to 9 days with the illness lasting from 2 to 9 days (31). HC can be treated with supportive care, and most illnesses are self-limiting (31).

HUS is the most common cause of kidney failure in children $(17,31)$. This illness usually requires intensive treatment, including blood transfusions and kidney 
dialysis; even with treatment, mortality is 3 to $5 \%$ (17). HUS manifests 7 to 10 days after the onset of diarrhea and can be characterized by pale skin, hemolytic anemia, thrombocytopenia, lack of urine production, edema, and kidney failure (17).

TTP resembles HUS, but occurs more commonly in adults than in children (17, 31). It is a rare illness characterized by hemolysis, thrombocytopenia, renal failure, neurological disorders, seizures, and stroke $(17,31)$. TTP is less predictable than HUS and death frequently results (31).

\section{Non-Intact Beef}

Steaks and roasts of lower tenderness are often subjected to mechanical tenderization, moisture enhancement, marination, or restructuring; these processes create non-intact beef products that have increased tenderness, juiciness, and flavor (36). Although the exterior surfaces of a carcass may become contaminated with pathogens during harvesting, the internal tissues are essentially sterile $(16,22)$. However, processes that create non-intact beef products can internalize pathogens that may have been present on the surface (36). This presents a potential health risk to the consumer; non-intact meat that is cooked to lower degrees of doneness have an increased risk of internalized pathogens surviving thermal inactivation (36). As a result of this potential health risk, FSIS has declared raw, non-intact beef adulterated if it contains $E$. coli O157:H7 (19). Although the prevalence of E. coli $\mathrm{O} 157: \mathrm{H} 7$ on the exterior surfaces of subprimal cuts is low (24), any surface bacteria present can be internalized during mechanical tenderization or moisture enhancement $(21,28)$. 


\section{Pre-Harvest Interventions}

Pre-harvest pathogen control systems aim to prevent or reduce the level of contamination found on the live animal prior to slaughter (36). Pre-harvest interventions proposed or used include diet manipulation, use of feed additives, competitive exclusion, and proper animal management practices such as pen management as well as clean feed and water (36).

Diet manipulation and feed additives are proposed methods of reducing the levels of pathogenic bacteria shed by cattle, especially E. coli O157:H7 (22). However, there have been no proven methods of dietary modifications that effectively reduce the levels of pathogenic bacteria in cattle destined for slaughter (22).

The competitive exclusion concept utilizes the benefits of probiotic bacteria to prevent or reduce colonization of pathogenic bacteria in the gastrointestinal tract of cattle (22). Probiotic bacteria have been utilized to reduce the level of E. coli $\mathrm{O} 157: \mathrm{H} 7$ in cattle; however, although the benefits of competitive exclusion have been demonstrated under experimental conditions, more research is needed in order to establish this concept in actual field conditions (22).

Water is a potential reservoir of $E$. coli $\mathrm{O} 157: \mathrm{H} 7$ in the pre-harvest environment (22). Drinking water treatment may be an effective control point to reduce pathogen levels in cattle (22). Chlorine at a level of $1.1 \mathrm{ppm}$ has been shown to reduce $E$. coli O157:H7 levels in drinking water by 4-log CFU/ml (22). 


\section{Hide-On Decontamination}

In order to reduce the contamination of beef carcasses during hide removal, several hide-on decontamination strategies are employed. Hide washing cabinets can be used to wash cattle after immobilization and exsanguination. These hide washing cabinets spray cattle with a solution of sodium hydroxide, ozonated water, electrolyzed oxidizing water, or trisodium phosphate. Sodium hydroxide reduced the prevalence of E. coli $\mathrm{O} 157: \mathrm{H} 7$ on hides from $44 \%$ to $17 \%$, and reduced the prevalence on preevisceration carcasses from $17 \%$ to $2 \%$ (27). Ozonated water reduced the prevalence of E. coli $\mathrm{O} 157: \mathrm{H} 7$ on hides from $89 \%$ to $31 \%$ and electrolyzed oxidizing water reduced $E$. coli $\mathrm{O} 157: \mathrm{H} 7$ from $82 \%$ to $35 \%$ (27). Trisodium phosphate had no additional reduction of $E$. coli $\mathrm{O} 157: \mathrm{H} 7$ beyond that of water washing, although water washing of hides alone reduced E. coli $\mathrm{O} 157: \mathrm{H} 7$ levels on the carcass by $1.5 \log \mathrm{CFU} / 100 \mathrm{~cm}^{2}$ (17).

Chemical dehairing can also be utilized to reduce bacterial contamination before hide removal. Chemical dehairing is used to remove hair, dirt, and fecal contamination from the hide in an attempt to reduce carcass contamination (17). The dehairing process results in a visibly cleaner carcass and reduces the requirement for zero tolerance trimming of fecal contamination (27). However, studies on chemical dehairing have had mixed results for bacterial reductions. Some studies have shown no significant differences between chemically dehaired cattle versus cattle processed conventionally $(22,37)$. Other studies have shown up to a 5-log reduction in E. coli O157:H7 recovered from the hides of cattle $(17,22,27)$. 


\section{Harvest Interventions}

Harvest interventions are designed to minimize introduction of contamination and to reduce or eliminate pathogenic bacteria through decontamination or sanitization procedures (36). These interventions include knife trimming, water washing, application of organic acids, steam vacuuming, and steam pasteurization.

Knife Trimming. Knife trimming of carcasses is required in slaughter facilities in order to remove all visible feces, milk, and ingesta in accordance with the USDAFSIS zero tolerance policy $(4,17,34)$. Every carcass is inspected for visible contamination; all visible contamination is removed by using a knife to remove the outer surface of the carcass in the contaminated area $(4,34)$. If not properly sanitized, the equipment used during trimming can potentially spread contamination (17).

Knife trimming has been shown to reduce mean aerobic plate counts (APC) by 1.4 to $1.6 \log \mathrm{CFU} / \mathrm{cm}^{2}$ and total coliform counts by 1.6 to $1.8 \log \mathrm{CFU} / \mathrm{cm}^{2}$ (37). Another study showed a $3.1 \log \mathrm{CFU} / \mathrm{cm}^{2}$ reduction in E. coli $\mathrm{O} 157: \mathrm{H} 7$, as well as a 4.0 to $4.3 \log \mathrm{CFU} / \mathrm{cm}^{2}$ reduction in APC, Enterobacteriaceae, total coliforms, thermotolerant coliforms, and generic E. coli (6). Knife trimming has also been demonstrated to reduce the level of E. coli $\mathrm{O} 157: \mathrm{H} 7$ contamination by 3.2 to $4.4 \mathrm{log}$ $\mathrm{CFU} / \mathrm{cm}^{2}$ (20).

Water Washing. Beef carcasses are typically water washed at the end of the slaughter line. This treatment is often used to remove visible soil, as well as hair, bone dust, and blood $(4,37)$. The effectiveness of water washing as a decontamination step varies according to water temperature. Washing with cold water has been shown to not 
be very effective at decontaminating beef carcasses; moreover, cold-water sprays can in some cases spread microbial contamination to other carcass surfaces $(3,4,34)$. Hot water has been shown to be much more effective at decontaminating beef carcasses. The decontamination effect of hot water is mainly though thermal inactivation, although the hot water can also detach the bacteria from carcass surfaces $(3,4)$.

Hot water washes have been shown to reduce $E$. coli $\mathrm{O} 157: \mathrm{H} 7$ levels 2.9 to 4.1 $\log \mathrm{CFU} / \mathrm{cm}^{2}$, depending upon carcass surface region (7). The hot water treatment was most effective at the clod region with a $4.1 \log \mathrm{CFU} / \mathrm{cm}^{2}$ reduction (7). The outside round, brisket, and flank revealed similar results, with a 4.0, 3.9, and $3.8 \log \mathrm{CFU} / \mathrm{cm}^{2}$, respectively (7). The hot water wash was least effective at the inside round region, with a reduction of $2.9 \log \mathrm{CFU} / \mathrm{cm}^{2}$ (7). This is likely due to the substantial amount of exposed lean tissue and a pronounced collar of fat at the edge of the lean, possibly allowing for bacteria to become imbedded in juncture of fat and lean and between muscle bundles of the lean surface $(7,20)$. Hot water washing also reduced APC, coliforms, and thermotolerant coliforms. The hot water spray reduced APC by 2.3 to 3.4 $\log \mathrm{CFU} / \mathrm{cm}^{2}$, with the outside round having the highest reduction and the inside round having the lowest reduction (7). Similar results were observed with total coliforms and thermotolerant coliforms, with reductions of 2.6 to 4.0 and 2.7 to $4.0 \log \mathrm{CFU} / \mathrm{cm}^{2}$, respectively (7). Moreover, the use of hot water resulted in less contamination of surfaces outside of the inoculated area than the use of cold water (7). When used on beef carcasses before evisceration, hot water reduced the prevalence of E. coli O157:H7 by $81 \%(5)$. 
Organic Acids. Organic acid sprays are frequently used in the beef industry as a decontamination step to control the growth of microorganisms $(17,22)$. Organic acids are typically applied as a rinse to the entire carcass surface (22). Lactic and acetic acids are the most commonly used acids, though many others have been researched (22). Organic acids are an effective surface treatment that kills or damages cells and prevents the attachment of Gram-negative bacteria $(3,4)$.

Lactic acid sprays have been shown to reduce $E$. coli $\mathrm{O} 157: \mathrm{H} 7$ contamination by 4.2 to $5.0 \log \mathrm{CFU} / \mathrm{cm}^{2}$, depending upon carcass surface region (6). Lactic acid also reduced APC, Enterobacteriaceae, total coliforms, thermotolerant coliforms, and generic $E$. coli by 4.3 to $4.6 \log \mathrm{CFU} / \mathrm{cm}^{2}$ (6). Greater reductions were observed when the lactic acid spray was combined with other intervention strategies, such as hot water washing and knife trimming (6). Similar results were found in another study; lactic acid was shown to reduce levels of $E$. coli $\mathrm{O} 157: \mathrm{H} 7$ by 3.0 to $4.9 \log \mathrm{CFU} / \mathrm{cm}^{2}$ (20). The lowest reduction was found on the inside round, where the surface characteristics of the region likely allowed the pathogen to become imbedded (20). In another study, lactic acid reduced the prevalence of E. coli $\mathrm{O} 157: \mathrm{H} 7$ by 35\% (5). Acetic acid has been shown to reduce $E$. coli $\mathrm{O} 157: \mathrm{H} 7$ by 2.4 to $3.7 \log \mathrm{CFU} / \mathrm{cm}^{2}$; the lowest reduction was again found on the inside round (20). Acidified sodium chlorite has been demonstrated to reduce $E$. coli $\mathrm{O} 157: \mathrm{H} 7$ by 3.0 to $5.1 \log \mathrm{CFU} / \mathrm{cm}^{2}$ (9). Sodium chlorite acidified with phosphoric acid produced greater overall reductions than sodium chlorite acidified with citric acid, with 4.5 and $3.8 \log \mathrm{CFU} / \mathrm{cm}^{2}$ reductions observed, respectively (9). When 
applied to hot carcass surfaces, peroxyacetic acid was able to reduce E. coli O157:H7 levels by $0.7 \log \mathrm{CFU} / \mathrm{cm}^{2}(25)$.

Steam Vacuuming. Steam vacuum systems use hand-held equipment that applies steam and a vacuum or steam-heated hot water and a vacuum in order to decontaminate small areas on the carcass $(4,34,37)$. Steam vacuuming is typically used on small areas of fecal contamination as an alternative to knife trimming; the combination of steam and vacuum inactivates bacteria and removes visible contamination $(8,22,37)$. Steam vacuuming improves the visible cleanliness of carcasses, reduces microbial contamination, reduces the need for knife trimming, and aids in meeting the zero tolerance policy for visible contamination (17).

Steam vacuuming reduced APC, Enterobacteriaceae, total coliforms, thermotolerant coliforms, and generic E. coli by 2.7 to $2.8 \log \mathrm{CFU} / \mathrm{cm}^{2}$ (8). When combined with other intervention strategies, steam vacuuming reduced the indicator organisms by 3.5 to $5.3 \log \mathrm{CFU} / \mathrm{cm}^{2}$ (8). Carcass surface region had no effect on the bacterial reductions, regardless of the treatment applied (8). However, steam vacuuming spread bacterial contamination from the inoculated area to uninoculated tissue; 2.0 to 3.2 $\log \mathrm{CFU} / \mathrm{cm}^{2}$ of indicator organisms were recovered from outside of the contaminated $\operatorname{area}(8)$.

Steam Pasteurization. Steam pasteurization uses an on-line cabinet system that removes surface water from the carcass, applies steam, and then chills the carcass with water (4). The surface water is removed in order to ensure adequate contact of the steam and the carcass is chilled to prevent discoloration (17). 


\section{Fabrication Interventions}

Interventions are commonly applied during harvest in order to reduce or eliminate microbial contamination. However, although many intervention systems exist for hot carcasses, interventions are applied to chilled beef less frequently and with variable results.

Although peroxyacetic acid can reduce E. coli $\mathrm{O} 157: \mathrm{H} 7$ levels when sprayed onto hot beef surfaces, it has no significant effect when applied to cold surfaces (25). No effect was also observed when using $1.0 \%$ lactic and $1.0 \%$ acetic acids. No significant differences were observed in APC when either lactic or acetic acid was applied $(1,14)$. However, when a $2 \%$ solution of lactic acid was applied to chilled beef significant reductions in E. coli occurred (11). When a $4 \%$ solution was applied at $55^{\circ} \mathrm{C}$

for $30 \mathrm{~s}$, E. coli $\mathrm{O} 157: \mathrm{H} 7$ was reduced by $2 \log \mathrm{CFU} / \mathrm{cm}^{2}$ (11). A 4\% lactic acid solution was also able to reduce APC by 3 to $3.3 \mathrm{log} \mathrm{CFU} / \mathrm{cm}^{2}$ in addition to reducing coliforms and generic E. coli below detectable levels (10). An additional study tested the effectiveness of trimming, hot water $\left(82^{\circ} \mathrm{C}\right), 2.5 \%$ lactic acid $\left(55^{\circ} \mathrm{C}\right)$, and $5 \%$ lactic acid $\left(55^{\circ} \mathrm{C}\right)$ and all treatments used resulted in a 1.0 to $1.1 \log \mathrm{CFU} / \mathrm{cm}^{2}$ reduction in $E$. coli O157:H7 (21). 


\section{CHAPTER III}

\section{MATERIALS AND METHODS}

\section{Product Preparation and Treatments}

Beef Loin, Top Sirloin Butt, Boneless (IMPS 184; (30)) subprimals ( $n=192)$ were obtained from a commercial beef processor on two occasions ( $n=96$ each time), vacuum packaged, boxed, and shipped via refrigerated carrier to the Rosenthal Meat Science and Technology Center at Texas A\&M University (College Station, TX). Upon arrival, half of the subprimals ( $n=48$ each time) were removed from their packages and the cap (Musculus gluteobiceps) was removed to make Beef Loin, Top Sirloin Butt, Semi Center-Cut, Boneless (IMPS 184A; (30)), which served as the "cap-off" subprimals with the remaining unaltered sirloins ( $n=48$ each time) serving as the "capon" subprimals. The cap-off subprimals were vacuum packaged and stored (approximately $2^{\circ} \mathrm{C}$ ) with the cap-on subprimals. The subprimals were divided into four replications, with 48 sirloins ( $n=24$ cap-on, $n=24$ cap-off) used each time.

Top sirloin butts were selected due to their use as one of the primary beef subprimals in non-intact applications in the food service industry. In addition, these subprimals allowed for the evaluation of both an original exterior carcass surface (fat surface) when the cap muscle was still attached and a lean surface when the cap muscle was removed.

Subprimals were assigned to one of four decontamination processes: 1) application of a water wash followed by full-surface trimming $(n=48), 2)$ application of 
a water wash followed by partial-surface trimming $(n=48), 3)$ application of fullsurface trimming followed by water wash $(n=48)$, and 4$)$ application of partial-surface trimming followed by water wash $(n=48)$. These processes resulted in seven total treatments: water wash, water wash followed by full-surface trimming, water wash followed by partial-surface trimming, full-surface trimming, full-surface trimming followed by water wash, partial-surface trimming, and partial-surface trimming followed by water wash.

The water wash was applied by rinsing the entire surface of the subprimal with room temperature tap water for 5 seconds. Full-surface trimming removed $5 \mathrm{~mm}$ of the dorsal and ventral surfaces. Partial-surface trimming removed $5 \mathrm{~mm}$ of only the dorsal surface.

\section{Bacterial Cultures and Inoculum Preparation}

Three strains of rifampicin-resistant E. coli O157:H7 (ATCC \# 43895, a strain provided by P. I. Tarr, Children's Hospital and Medical Center, Seattle, WA that was originally isolated from ground beef implicated in the 1993 Washington State outbreak, and a Food Microbiology Laboratory strain isolated from cattle feces) were obtained from the Food Microbiology Laboratory, Department of Animal Science at Texas A\&M University. These three cultures were maintained on tryptic soy agar (TSA; BD Diagnostic Systems, Sparks, MD) slants and stored at room temperature (approximately $25^{\circ} \mathrm{C}$ ). For each inoculation day of the experiment, strains were cultured in tryptic soy broth (TSB; BD Diagnostic Systems) and incubated $18 \mathrm{~h}$ at $35^{\circ} \mathrm{C}$. Liquid cultures were 
centrifuged for $15 \mathrm{~min}$ at $1620 \times g$ and washed with phosphate buffered saline (PBS) three times. A bacterial cocktail was prepared by mixing equal volumes of each culture and then was diluted to the appropriate inoculum levels in $0.1 \%$ peptone.

\section{Subprimal Inoculation}

Ninety-six top sirloin butts ( $n=48$ cap-on, $n=48$ cap-off) were inoculated with approximately $10^{2} \mathrm{CFU} / \mathrm{cm}^{2}$ of E. coli $\mathrm{O} 157: \mathrm{H} 7$ (low-inoculum), and ninety-six top sirloin butts ( $n=48$ cap-on, $n=48$ cap-off) were inoculated with approximately $10^{4}$ $\mathrm{CFU} / \mathrm{cm}^{2}$ of $E$. coli $\mathrm{O} 157: \mathrm{H} 7$ (high-inoculum). The low-inoculum represents the minimum level that could be applied consistently, and the high-inoculum represents levels greater than those typically found on subprimals, which would allow tracking of reductions in microbial numbers using the water wash and trimming decontamination methods.

Before inoculation, a $100-\mathrm{cm}^{2}$ area of each top sirloin butt was delineated on the dorsal surface of each subprimal with a sterile template and the corners were marked with sterile stainless-steel pins in order to identify the inoculated area during sampling. Each subprimal was inoculated with $0.5 \mathrm{ml}$ of the cocktail by evenly spreading it over the $100-\mathrm{cm}^{2}$ area using a sterile disposable plastic spreader. Following inoculation, the subprimals were vacuum packaged, submerged in a hot water bath to heat shrink the packaging, and stored under refrigeration $\left(2^{\circ} \mathrm{C}\right)$ for either 0,14 , or 28 days. 


\section{Sample Collection}

Before inoculation, two $10-\mathrm{cm}^{2}(2 \mathrm{~mm}$ in depth) surface samples $(n=48)$ of top sirloin butts were excised and composited $\left(20-\mathrm{cm}^{2}\right.$ total area) from every fourth subprimal using a sterile stainless-steel borer, scalpel, and forceps in order to evaluate possible natural presence of the marker organism.

Prior to opening, sponge samples were collected from the exterior surface of the vacuum package $(n=192)$. The packages then were opened aseptically using a sterile scalpel, and the subprimals were removed. Ten ml samples of purge were collected from the day $14(n=64)$ and day $28(n=64)$ subprimals in order to determine the level of purge contamination. No purge was available to collect for the day 0 subprimals; therefore, the inside of the vacuum package bag was rinsed with $10 \mathrm{ml}$ of $0.1 \%$ peptone. The $0.1 \%$ peptone then was collected to simulate purge $(n=64)$. In order to evaluate contamination levels and the extent of translocation before treatments were applied, two $10-\mathrm{cm}^{2}\left(2 \mathrm{~mm}\right.$ in depth) samples were excised and composited $\left(20-\mathrm{cm}^{2}\right.$ total area) from each of the following subprimal surfaces: the inoculated surface area $(n=192)$, a site adjacent to the inoculated surface area $(n=192)$, and the opposite side $(n=192)$ using a sterile stainless-steel borer, scalpel, and forceps.

After the first treatment was applied, two $10-\mathrm{cm}^{2}$ (2 $\mathrm{mm}$ in depth) samples were excised and composited $\left(20-\mathrm{cm}^{2}\right.$ total area) from each of the subprimal surfaces. The subprimals that received a water wash as the first treatment $(n=96)$ had samples excised from the inoculated surface area $(n=96)$, a site adjacent to the inoculated surface area $(n$ $=96)$, and the opposite side $(n=96)$. As a result of the trimming process, the inoculated 
surface area could no longer be distinguished from the area adjacent to the inoculated surface area. Therefore, the subprimals that were full-surface trimmed for the first treatment $(n=48)$ had samples excised from the inoculated side $(n=48)$ and the opposite side $(n=48)$. Subprimals that were partial-surface trimmed for the first treatment $(n=48)$ also had samples excised from the inoculated side $(n=48)$ and the opposite side $(n-48)$. Following the second treatment, two $10-\mathrm{cm}^{2}(2 \mathrm{~mm}$ in depth) samples were excised and composited $\left(20-\mathrm{cm}^{2}\right.$ total area) from each of the remaining subprimal surfaces: the inoculated side $(n=192)$ and the opposite side $(n=192)$.

\section{Microbiological Examination}

Rifampicin resistance and inoculum levels were confirmed by plating the high and low inoculum on prepoured and dried rifampicin-tryptic soy agar (rif-TSA) plates with a sterile bent glass rod. Rif-TSA was prepared by adding a solution of $0.1 \mathrm{~g}$ of rifampicin (Sigma-Aldrich, St. Louis, MO) dissolved in $5 \mathrm{ml}$ methanol to 1 liter of autoclaved and cooled $\left(55^{\circ} \mathrm{C}\right) \mathrm{TSA}$. Each sponge sample was hand massaged in $25 \mathrm{ml}$ of $0.1 \%$ peptone for $1 \mathrm{~min}$. Composite samples (including background samples) were placed in a sterile stomacher bag to which $99 \mathrm{ml}$ of $0.1 \%$ peptone was added. The samples then were pummeled for 1 min using a Stomacher-400 (Tekmar Company, Cincinnati, OH). For each sample (sponge, purge, and composite samples), counts were determined by plating appropriate decimal dilutions on rif-TSA plates with a sterile bent glass rod. Plates were incubated $24 \mathrm{~h}$ at $35^{\circ} \mathrm{C}$. Colonies were counted, recorded, and reported as $\log \mathrm{CFU} / \mathrm{cm}^{2}$ following Culture Methods for Enumeration of 
Microorganisms (38). In total, 192 sponge samples, 192 purge samples, and 1440 subprimal surface composites were analyzed for a total of 1824 microbiological data points.

\section{Statistical Analysis}

Microbiological count data were transformed into logarithms before obtaining means and performing statistical analyses. In the case of counts below the detection limit of the counting method, a number between 0 and the lowest detection limit was used in order to facilitate the data analysis. Data were analyzed using PROC GLM of SAS (SAS Institute, Inc., Cary, NC) to perform analysis of variance. The dataset was sorted by inoculum level and location (inoculation site, adjacent site, and opposite side, and the main effects of storage day, cap (on or off), and treatment (combinations of wash and trim treatments) and the three-way interaction was analyzed in a full model. For significant main and interaction effects, means were separated using the pdiff procedure. 


\section{CHAPTER IV}

\section{RESULTS AND DISCUSSION}

Translocation from the inoculated surface area to other areas of the subprimal was observed for all top sirloin butts (Tables 1, 2, and 3). Counts recovered at the inoculation site were similar to the original inoculum level applied to that area, with the adjacent site having counts 1.0 to $2.0 \log _{10} \mathrm{CFU} / \mathrm{cm}^{2}$ lower and the opposite side having the lowest levels of E. coli $\mathrm{O} 157: \mathrm{H} 7$ recovered. For the opposite side of the low inoculated sirloins, initial counts were at or below the detection limit of $0.7 \log _{10}$ $\mathrm{CFU} / \mathrm{cm}^{2}$. Counts of E. coli $\mathrm{O} 157: \mathrm{H} 7$ recovered varied by storage day and the type of subprimal (cap-on vs. cap-off), but no microbiologically relevant differences were detected; less than $1.0 \log _{10} \mathrm{CFU} / \mathrm{cm}^{2}$ difference was observed among storage day and between cap-on and cap-off sirloins. None of the controls detected any rifampicinresistant organisms in the background flora of the subprimals (data not shown).

The translocation to other subprimal surfaces could have been caused by the purge in the vacuum-packages contaminating the rest of the sirloin. The levels of E. coli O157:H7 found in the purge were similar to the initial inoculum level for both the high and low inocula. The high-inoculated sirloins had an average of $4.4 \log _{10} \mathrm{CFU} / \mathrm{ml}$ found in the purge, while the low-inoculated sirloins had an average of $2.1 \log _{10} \mathrm{CFU} / \mathrm{ml}$ (not in tabular form). The purge likely was able to contaminate the other subprimal surfaces when the sirloins were removed from packaging; handling of the subprimals allowed the purge to move within the package and contact other subprimal surfaces. This could pose 
a potential concern for beef processors beyond translocation within a vacuum-package; if the purge from subprimals is allowed to contaminate food-contact surfaces, E. coli O157:H7 could spread to other subprimals processed in the vicinity of the contaminated subprimal.

Contamination was also detected on the exterior surfaces of the vacuum-package bags. High-inoculated top sirloin butts had a higher frequency of contamination than low-inoculated sirloins; $12.5 \%$ of the bags from high-inoculated sirloins were contaminated, as opposed to only $1 \%$ of the bags from low-inoculated sirloins. As with the purge, this could be a potential concern for processors; contaminated bags could spread E. coli $\mathrm{O} 157: \mathrm{H} 7$ to food-contact surfaces, leading to the contamination of other subprimals.

Water washing alone had little to no effect on the level of E. coli $\mathrm{O} 157: \mathrm{H} 7$ recovered from any subprimal surface, for both the high and low inoculated sirloins (Table 1, 2, and 3). Less than a $1.0 \log _{10} \mathrm{CFU} / \mathrm{cm}^{2}$ difference was observed between the counts recovered before treatment and the counts recovered after water washing. Water washing was not as effective in this study as in previous research; however, previous research has shown that the effectiveness of water washing as a decontamination method varies according to water temperature. Washing with cold water has been shown to not be very effective at decontaminating beef carcasses; moreover, cold-water sprays can in some cases spread microbial contamination to other carcass surfaces $(3,4,34)$. Hot water has been shown to be much more effective at decontaminating beef carcasses. The decontamination effect of hot water is mainly though thermal inactivation, although the 
hot water can also detach the bacteria from carcass surfaces $(3,4)$. Hot water washes have been shown to reduce E. coli $\mathrm{O} 157: \mathrm{H} 7$ levels 2.9 to $4.1 \log _{10} \mathrm{CFU} / \mathrm{cm}^{2}$, depending upon carcass surface region (7). Moreover, the use of hot water resulted in less contamination of surfaces outside of the inoculated area than the use of cold water (7). When used on beef carcasses before evisceration, hot water reduced the prevalence of $E$. coli $\mathrm{O} 157: \mathrm{H} 7$ by $81 \%(5)$. When applied to chilled beef subprimals, hot water was able to reduce $E$. coli $\mathrm{O} 157: \mathrm{H} 7$ levels by $1.0 \log _{10} \mathrm{CFU} / \mathrm{cm}^{2}$ (21). Therefore, the water washing treatment in this study was likely less effective due to the use of room temperature water.

Due to the removal of the entire dorsal surface during the trimming decontamination methods, the inoculation site was no longer distinguishable from the adjacent area. Therefore, to facilitate the analyses, the counts from the inoculated side of trimmed subprimals were compared to both the inoculation site and the adjacent area of the initial and water-washed counts. Full and partial-surface trimming alone significantly decreased the counts recovered from the dorsal surface (Table 1 and 2). With one exception, the high-inoculated sirloins had E. coli O157:H7 levels at or below $1.0 \log _{10} \mathrm{CFU} / \mathrm{cm}^{2}$; the majority of the low-inoculated sirloins had E. coli O157:H7 levels below the detection limit. However, on the opposite side of high-inoculated subprimals, full-surface trimming was much more effective than partial-surface trimming (Table 3). Partially trimmed sirloins often had counts at least 0.5 to $1.0 \log _{10}$ $\mathrm{CFU} / \mathrm{cm}^{2}$ higher than the fully trimmed sirloins. For the low-inoculated subprimals, no microbiologically relevant differences were observed between the fully trimmed and 
partially trimmed sirloins. However, bacterial reductions obtained by trimming under laboratory conditions, using sterile equipment, may not represent the reductions that can be achieved during normal fabrication interventions.

Water washing combined with a trimming step had little to no additional effect on the counts recovered, with less than a $0.5 \log _{10} \mathrm{CFU} / \mathrm{cm}^{2}$ difference often detected between trimming alone and trimming combined with water washing. Moreover, the order in which the treatments were applied had no significant effect on the counts recovered. 


\section{CHAPTER V}

\section{CONCLUSIONS}

E. coli $\mathrm{O} 157: \mathrm{H} 7$ is a major food safety concern for the beef industry. For both high and low inoculated top sirloin butts, contamination of other subprimal surfaces was found after vacuum packaging, but no microbiologically significant differences were observed among storage days or between cap-on and cap-off sirloins. Processors should understand that any surface contamination could spread from one location to another in vacuum-packaged top sirloin butts. Of the treatments used, water washing was the least effective for both high and low inoculated subprimals. Full trimming, with or without a water wash treatment, proved to be the most effective treatment used. Although partial trimming did have comparable levels of E. coli $\mathrm{O} 157: \mathrm{H7}$ on the inoculated side, the counts observed on the opposite side were often significantly higher than those found on the fully trimmed subprimals. However, the more reasonable level of contamination found in the low-inoculated top sirloin butts revealed no significant differences between full trimming and partial trimming, with or without a water wash treatment. Processors of non-intact beef products must consider the potential hazards that may occur in this process and properly address these concerns in their food safety programs 


\section{REFERENCES}

1. Acuff, G. R., C. Vanderzant, J. W. Savell, D. K. Jones, D. B. Griffin, and J. G. Ehlers. 1987. Effect of acid decontamination of beef subprimal cuts on the microbiological and sensory characteristics of steaks. Meat Sci. 19:217-226.

2. Batt, C. A. 1999. Escherichia coli, p. 633-640. In C.A. Batt, R.K. Robinson, and P.D. Patel (ed.), Encyclopedia of Food Microbiology. Academic Press, New York.

3. Bolder, N. M. 1997. Decontamination of meat and poultry carcasses. Trends Food Sci. Technol. 8:221-227.

4. Bolton, D. J., A. M. Doherty, and J. J. Sheridan. 2001. Beef HACCP: intervention and non-intervention systems. Int. J. Food Microbiol. 66:119-129.

5. Bosilevac, J. M., X. Nou, G. A. Barkocy-Gallagher, T. M. Arthur, and M. Koohmaraie. 2006. Treatments using hot water instead of lactic acid reduce levels of aerobic bacteria and Enterobacteriaceae and reduce the prevalence of Escherichia coli $\mathrm{O} 157: \mathrm{H} 7$ on preevisceration beef carcasses. J. Food Protect. 69:1808-1813.

6. Castillo, A., L. M. Lucia, K. J. Goodson, J. W. Savell, and G. R. Acuff. 1998. Comparison of water wash, trimming, and combined hot water and lactic acid treatments for reducing bacteria of fecal origin on beef carcasses. J. Food Protect. 61:823-828. 
7. Castillo, A., L. M. Lucia, K. J. Goodson, J. W. Savell, and G. R. Acuff. 1998. Use of hot water for beef carcass decontamination. J. Food Protect. 61:19-25.

8. Castillo, A., L. M. Lucia, K. J. Goodson, J. W. Savell, and G. R. Acuff. 1999. Decontamination of beef carcass surface tissue by steam vacuuming alone and combined with hot water and lactic acid sprays. J. Food Protect. 62:146-151.

9. Castillo, A., L. M. Lucia, G. K. Kemp, and G. R. Acuff. 1999. Reduction of Escherichia coli O157:H7 and Salmonella Typhimurium on beef carcass surfaces using acidified sodium chlorite. J. Food Protect. 62:580-584.

10. Castillo, A., L. M. Lucia, I. Mercado, and G. R. Acuff. 2001. In-plant evaluation of a lactic acid treatment for reduction of bacteria on chilled beef carcasses. $J$. Food Protect. 64:738-740.

11. Castillo, A., L. M. Lucia, D. B. Roberson, T. H. Stevenson, I. Mercado, and G. R. Acuff. 2001. Lactic acid sprays reduce bacterial pathogens on cold beef carcass surfaces and in subsequently produced ground beef. J. Food Protect. 64:58-62.

12. Centers for Disease Control and Prevention. 2010. CDC estimates of foodborne illness in the United States. Available at: http://www.cdc.gov/foodborneburden/2011-foodborne-estimates.html. Accessed 21 December 2010.

13. Desmarchelier, P., and N. Fegan. 2002. Escherichia coli, p. 948-954. In J.W. Fuquay, P.F. Fox, and H. Roginski (ed.), Encyclopedia of Dairy Sciences. Academic Press, New York. 
14. Dixon, Z. R., C. Vanderzant, G. R. Acuff, J. W. Savell, and D. K. Jones. 1987. Effect of acid treatment of beef strip loin steaks on microbiological and sensory characteristics. Int. J. Food Microbiol. 5:181-186.

15. Dykes, G. A. 2004. Escherichia coli O157:H7, p. 781-786. In W.K. Jensen, C. Devine, and M. Dikeman (ed.), Encyclopedia of Meat Sciences. Academic Press, New York.

16. Echeverry, A., J. C. Brooks, M. F. Miller, J. A. Collins, G. H. Loneragan, and M. M. Brashears. 2009. Validation of intervention strategies to control Escherichia coli O157:H7 and Salmonella Typhimurium DT 104 in mechanically tenderized and brine-enhanced beef. J. Food Protect. 72:1616-1623.

17. Edwards, J. R., and D. Y. C. Fung. 2006. Prevention and decontamination of Escherichia coli $\mathrm{O} 157: \mathrm{H} 7$ on raw beef carcasses in commercial beef abattoirs. $J$. Rapid Methods Autom. Microbiol. 14:1-95.

18. Elder, R. O., J. E. Keen, G. R. Siragusa, G. A. Barkocy-Gallagher, M. Koohmaraie, and W. W. Laegreid. 2000. Correlation of enterohemorrhagic Escherichia coli $\mathrm{O} 157$ prevalence in feces, hides, and carcasses of beef cattle during processing. Proc. Natl. Acad. Sci. USA. 97:2999-3003.

19. Food Safety and Inspection Service. 2002. Comparative risk assessment for intact (non-tenderized) and non-intact (tenderized) beef: executive summary. Available at:

http://www.fsis.usda.gov/PDF/Beef_Risk_Assess_ExecSumm_Mar2002.pdf. Accessed 19 February 2011. 
20. Hardin, M. D., G. R. Acuff, L. M. Lucia, J. S. Oman, and J. W. Savell. 1995. Comparison of methods for decontamination from beef carcass surfaces. J. Food Protect. 58:368-374.

21. Heller, C. E., J. A. Scanga, J. N. Sofos, K. E. Belk, W. Warren-Serna, G. R. Bellinger, R. T. Bacon, M. L. Rossman, and G. C. Smith. 2007. Decontamination of beef subprimal cuts intended for blade tenderization or moisture enhancement. J. Food Protect. 70:1174-1180.

22. Huffman, R. D. 2002. Current and future technologies for the decontamination of carcasses and fresh meat. Meat Sci. 62:285-294.

23. Kaper, J. B. 1998. Enterohemorrhagic Escherichia coli. Curr. Opin. Microbiol. $1: 103-108$.

24. Kennedy Jr., J. E., S. K. Williams, T. Brown, and P. Minerich. 2006. Prevalence of Escherichia coli $\mathrm{O} 157: \mathrm{H} 7$ and indicator organisms on the surface of intact subprimal beef cuts prior to further processing. J. Food Protect. 69:1514-1517.

25. King, D. A., L. M. Lucia, A. Castillo, G. R. Acuff, K. B. Harris, and J. W. Savell. 2005. Evaluation of peroxyacetic acid as a post-chilling intervention for control of Escherichia coli $\mathrm{O} 157: \mathrm{H7}$ and Salmonella Typhimurium on beef carcass surfaces. Meat Sci. 69:401-407.

26. Kirkhorn, S. R. 2008. Food safety issues: a summary report of a panel session addressing pre- and post-harvest strategies to improve public health. J. Agromed. $13: 233-236$. 
27. Koohmaraie, M., T. M. Arthur, J. M. Bosilevac, M. Guerini, S. D. Shackelford, and T. L. Wheeler. 2005. Post-harvest interventions to reduce/eliminate pathogens in beef. Meat Sci. 71:79-91.

28. Luchansky, J. B., R. K. Phebus, H. Thippareddi, and J. E. Call. 2008. Translocation of surface-inoculated Escherichia coli $\mathrm{O} 157: \mathrm{H} 7$ into beef subprimals following blade tenderization. J. Food Protect. 71:2190-2197.

29. Mead, P. S., L. Slutsker, V. Dietz, L. F. McCaig, J. S. Bresee, C. Shapiro, P. M. Griffin, and R. V. Tauxe. 1999. Food-related illness and death in the United States. Emerg. Infect. Dis. 5:607-625.

30. North American Meat Processors Association. 2010. The meat buyer's guide. $6^{\text {th }}$ ed. North American Meat Processors Association, Reston, VA.

31. Park, S., R. W. Worobo, and R. A. Durst. 2001. Escherichia coli O157:H7 as an emerging foodborne pathogen: a literature review. Crit. Rev. Biotechnol. 21:2748.

32. Rasmussen, M. A., and T. A. Casey. 2001. Environmental and food safety aspects of Escherichia coli $\mathrm{O} 157: \mathrm{H} 7$ infections in cattle. Crit. Rev. Microbiol. 27:57-73.

33. Scallan, E., R. M. Hoekstra, F. J. Angulo, R. V. Tauxe, M.-A. Widdowson, S. L. Roy, J. L. Jones, and P. M. Griffin. 2011. Foodborne illness acquired in the United States-major pathogens. Emerg. Infect. Dis. 17:1-21. 
34. Sheridan, J. J. 2004. Decontamination, p. 389-396. In W.K. Jensen, C. Devine, and M. Dikeman (ed.), Encyclopedia of Meat Sciences. Academic Press, New York.

35. Shugart, L. R. 2005. E. coli (Escherichia coli), p. 115-116. In P. Wexler (ed.), Encyclopedia of Toxicology. Academic Press, New York.

36. Sofos, J. N., and I. Geornaras. 2010. Overview of current meat hygiene and safety risks and summary of recent studies on biofilms, and control of Escherichia coli $\mathrm{O} 157: \mathrm{H7}$ in nonintact, and Listeria monocytogenes in ready-toeat, meat products. Meat Sci. 86:2-14.

37. Sofos, J. N., and G. C. Smith. 1998. Nonacid meat decontamination technologies: model studies and commercial applications. Int. J. Food Microbiol. 44:171-188.

38. Swanson, K. M. J., R. L. Petran, and J. H. Hanlin. 2001. Culture methods for enumeration of microorganisms, p. 53-62. In F.P. Downes and K. Itō (ed.), Compendium of methods for the microbiological examination of foods. American Public Health Association, Washington, DC.

39. U.S. Department of Agriculture, Food Safety and Inspection Service. 2009. E. coli O157:H7 Summary Data. Available at: http://www.fsis.usda.gov/Science/Ecoli_O157_Summary_Tables/index.asp. Accessed 25 November 2009. 


\section{APPENDIX A}

\section{TABLES}

TABLE 1. Least squares means for storage day $\times$ cap $\times$ treatment effect on counts $\left(\log _{10} C_{F U / m^{2}}\right)$ of E. coli O157:H7 at the inoculation site ${ }^{a}$ or inoculated side of top sirloin butts

\begin{tabular}{|c|c|c|c|c|c|c|c|}
\hline & & \multicolumn{3}{|c|}{ Cap on ${ }^{d}$} & \multicolumn{3}{|c|}{ Cap off } \\
\hline & & Day $0^{e}$ & Day 14 & Day 28 & Day 0 & Day 14 & Day 28 \\
\hline SEM & High $^{b}$ & & & & & & \\
\hline$\overline{0.092} 87$ & $\overline{\text { Initial }}^{f}$ & $4.98 \mathrm{~A}^{g}$ & $4.79 \mathrm{~A}$ & $4.62 \mathrm{~A}$ & $4.97 \mathrm{~A}$ & $4.77 \mathrm{~A}$ & $4.67 \mathrm{~A}$ \\
\hline 0.1313 & WW & $4.76 \mathrm{~A}$ & $4.66 \mathrm{~A}$ & $4.28 \mathrm{~B}$ & $4.81 \mathrm{~A}$ & $4.43 \mathrm{~B}$ & $4.44 \mathrm{~A}$ \\
\hline 0.1857 & WWFT & $<0.70 \mathrm{~B}^{h}$ & $0.95 \mathrm{~B}$ & $<0.70 \mathrm{C}$ & $0.93 \mathrm{~B}$ & $1.23 \mathrm{C}$ & $1.43 \mathrm{~B}$ \\
\hline 0.1857 & WWPT & $<0.70 \mathrm{~B}$ & $0.75 \mathrm{~B}$ & $<0.70 \mathrm{C}$ & $0.95 \mathrm{~B}$ & $0.70 \mathrm{C}$ & $0.73 \mathrm{~B}$ \\
\hline 0.1857 & FTWW & $<0.70 \mathrm{~B}$ & $0.85 \mathrm{~B}$ & $<0.70 \mathrm{C}$ & $1.05 \mathrm{~B}$ & $1.60 \mathrm{C}$ & $1.13 \mathrm{~B}$ \\
\hline 0.1857 & PTWW & $<0.70 \mathrm{~B}$ & $0.75 \mathrm{~B}$ & $0.80 \mathrm{C}$ & $0.88 \mathrm{~B}$ & $1.45 \mathrm{C}$ & $0.90 \mathrm{~B}$ \\
\hline 0.1857 & FT & $<0.70 \mathrm{~B}$ & $0.85 \mathrm{~B}$ & $<0.70 \mathrm{C}$ & $0.75 \mathrm{~B}$ & $1.00 \mathrm{C}$ & $0.83 \mathrm{~B}$ \\
\hline 0.1857 & $\begin{array}{l}\text { PT } \\
\text { Low }^{c}\end{array}$ & 0.73 в & $<0.70 \mathrm{~B}$ & $<0.70 \mathrm{C}$ & $<0.70 \mathrm{~B}$ & $0.73 \mathrm{C}$ & $1.40 \mathrm{~B}$ \\
\hline 0.06242 & $\overline{\text { Initial }}$ & $2.91 \mathrm{~A}$ & $2.36 \mathrm{~A}$ & $2.33 \mathrm{~A}$ & $2.66 \mathrm{~A}$ & $2.30 \mathrm{~A}$ & $2.27 \mathrm{~A}$ \\
\hline 0.08828 & WW & $2.38 \mathrm{~B}$ & $2.20 \mathrm{~A}$ & $2.19 \mathrm{~A}$ & $2.51 \mathrm{~A}$ & $2.35 \mathrm{~A}$ & $2.24 \mathrm{~A}$ \\
\hline 0.1248 & WWFT & $<0.70 \mathrm{C}$ & $<0.70 \mathrm{~B}$ & $<0.70 \mathrm{~B}$ & $<0.70 \mathrm{~B}$ & $<0.70 \mathrm{~B}$ & $<0.70 \mathrm{~B}$ \\
\hline 0.1248 & WWPT & $<0.70 \mathrm{C}$ & $0.75 \mathrm{~B}$ & $<0.70 \mathrm{~B}$ & $<0.70 \mathrm{~B}$ & $<0.70 \mathrm{~B}$ & $<0.70 \mathrm{~B}$ \\
\hline 0.1248 & FTWW & $<0.70 \mathrm{C}$ & $<0.70 \mathrm{~B}$ & $<0.70 \mathrm{~B}$ & $<0.70 \mathrm{~B}$ & $<0.70 \mathrm{~B}$ & $<0.70 \mathrm{~B}$ \\
\hline 0.1248 & PTWW & $<0.70 \mathrm{C}$ & $<0.70 \mathrm{~B}$ & $<0.70 \mathrm{~B}$ & $<0.70 \mathrm{~B}$ & $<0.70 \mathrm{~B}$ & $<0.70 \mathrm{~B}$ \\
\hline 0.1248 & $\mathrm{FT}$ & $<0.70 \mathrm{C}$ & $<0.70 \mathrm{~B}$ & $<0.70 \mathrm{~B}$ & $<0.70 \mathrm{~B}$ & $<0.70 \mathrm{~B}$ & $<0.70 \mathrm{~B}$ \\
\hline 0.1248 & PT & $<0.70 \mathrm{C}$ & $<0.70 \mathrm{~B}$ & $<0.70 \mathrm{~B}$ & $<0.70 \mathrm{~B}$ & $<0.70 \mathrm{~B}$ & $0.73 \mathrm{~B}$ \\
\hline
\end{tabular}

${ }^{a}$ Inoculation site was a $100 \mathrm{~cm}^{2}$ area on the dorsal surface. Inoculated side was the entire dorsal surface. Adjacent site was an area on the dorsal surface adjacent to the inoculation site. The opposite side was the ventral side.

${ }^{b}$ High-inoculum level $=$ approximately $4.8 \log _{10} \mathrm{CFU} / \mathrm{cm}^{2}$.

${ }^{c}$ Low inoculum level $=$ approximately $2.5 \log _{10} \mathrm{CFU} / \mathrm{cm}^{2}$.

${ }^{d}$ Cap on is the Beef Loin, Top Sirloin Butt, Boneless (IMPS 184) and cap off is the Beef Loin, Top Sirloin Butt, Center Cut, Boneless, Cap Off (IMPS 184B).

${ }^{e}$ Top sirloin butts were stored under refrigeration $\left(2^{\circ} \mathrm{C}\right)$ for either 0,14 or 28 days.

${ }^{f}$ Initial refers to counts before treatment was applied. Water wash (WW) refers to washing the entire exterior surface with tap water. Full trim (FT) removed all exterior surfaces. Partial trim (PT) removed only the dorsal surface.

$g$ Numbers within columns within inoculation levels with different letters significantly differ $(P<0.05)$.

${ }^{h}$ Detection limit $=0.7 \log _{10} \mathrm{CFU} / \mathrm{cm}^{2}$ 
TABLE 2. Least squares means for storage day $\times$ cap $\times$ treatment effect on counts $\left(\log _{10} C F U / \mathrm{cm}^{2}\right)$ of $\mathrm{E}$. coli O157:H7 at the adjacent site ${ }^{a}$ or inoculated side of top sirloin butts

\begin{tabular}{|c|c|c|c|c|c|c|c|}
\hline & & \multicolumn{3}{|c|}{ Cap on $^{d}$} & \multicolumn{3}{|c|}{ Cap off } \\
\hline & & Day $0^{e}$ & Day 14 & Day 28 & Day 0 & Day 14 & Day 28 \\
\hline SEM & $\underline{\text { High }}^{b}$ & & & & & & \\
\hline$\overline{0.1303}$ & $\overline{\text { Initialf }^{f}}$ & $3.06 \mathrm{~A}^{g}$ & $2.66 \mathrm{~A}$ & $2.58 \mathrm{~A}$ & $3.44 \mathrm{~A}$ & $3.04 \mathrm{~A}$ & $3.05 \mathrm{~A}$ \\
\hline 0.1842 & WW & $2.68 \mathrm{~A}$ & $2.33 \mathrm{~A}$ & $2.03 \mathrm{~B}$ & $3.41 \mathrm{~A}$ & $3.01 \mathrm{~A}$ & $3.28 \mathrm{~A}$ \\
\hline 0.2606 & WWFT & $<0.70 \mathrm{~B}^{h}$ & $0.95 \mathrm{~B}$ & $<0.70 \mathrm{C}$ & $0.93 \mathrm{~B}$ & $1.23 \mathrm{BC}$ & $1.43 \mathrm{~B}$ \\
\hline 0.2606 & WWPT & $<0.70 \mathrm{~B}$ & $0.75 \mathrm{~B}$ & $<0.70 \mathrm{C}$ & $0.95 \mathrm{~B}$ & $0.70 \mathrm{C}$ & $0.73 \mathrm{~B}$ \\
\hline 0.2606 & FTWW & $<0.70 \mathrm{~B}$ & $0.85 \mathrm{~B}$ & $<0.70 \mathrm{C}$ & $1.05 \mathrm{~B}$ & $1.60 \mathrm{~B}$ & $1.13 \mathrm{~B}$ \\
\hline 0.2606 & PTWW & $<0.70 \mathrm{~B}$ & $0.75 \mathrm{~B}$ & $0.80 \mathrm{C}$ & $0.88 \mathrm{~B}$ & $1.45 \mathrm{~B}$ & $0.90 \mathrm{~B}$ \\
\hline 0.2606 & FT & $<0.70 \mathrm{~B}$ & $0.85 \mathrm{~B}$ & $<0.70 \mathrm{C}$ & 0.75 B & $1.00 \mathrm{BC}$ & $0.83 \mathrm{~B}$ \\
\hline 0.2606 & $\begin{array}{l}\text { PT } \\
\underline{\mathbf{L o w}}^{c}\end{array}$ & 0.73 в & $<0.70 \mathrm{~B}$ & $<0.70 \mathrm{C}$ & $<0.70 \mathrm{~B}$ & $0.73 \mathrm{C}$ & $1.40 \mathrm{~B}$ \\
\hline 0.08805 & $\overline{\text { Initial }}$ & $1.25 \mathrm{~A}$ & $0.97 \mathrm{~A}$ & $<0.70 \mathrm{~B}$ & $1.08 \mathrm{~A}$ & $0.88 \mathrm{~A}$ & $0.95 \mathrm{~A}$ \\
\hline 0.1245 & WW & $1.11 \mathrm{~A}$ & $0.76 \mathrm{AB}$ & $0.94 \mathrm{~A}$ & $1.20 \mathrm{~A}$ & $0.88 \mathrm{~A}$ & $0.68 \mathrm{AB}$ \\
\hline 0.1761 & WWFT & $<0.70 \mathrm{~B}$ & $<0.70 \mathrm{~B}$ & $<0.70 \mathrm{~B}$ & $<0.70 \mathrm{~B}$ & $<0.70 \mathrm{~B}$ & $<0.70 \mathrm{~B}$ \\
\hline 0.1761 & WWPT & $<0.70 \mathrm{~B}$ & $0.75 \mathrm{AB}$ & $<0.70 \mathrm{~B}$ & $<0.70 \mathrm{~B}$ & $<0.70 \mathrm{~B}$ & $<0.70 \mathrm{~B}$ \\
\hline 0.1761 & FTWW & $<0.70 \mathrm{~B}$ & $<0.70 \mathrm{~B}$ & $<0.70 \mathrm{~B}$ & $<0.70 \mathrm{~B}$ & $<0.70 \mathrm{~B}$ & $<0.70 \mathrm{~B}$ \\
\hline 0.1761 & PTWW & $<0.70 \mathrm{~B}$ & $<0.70 \mathrm{~B}$ & $<0.70 \mathrm{~B}$ & $<0.70 \mathrm{~B}$ & $<0.70 \mathrm{~B}$ & $<0.70 \mathrm{~B}$ \\
\hline 0.1761 & FT & $<0.70 \mathrm{~B}$ & $<0.70 \mathrm{~B}$ & $<0.70 \mathrm{~B}$ & $<0.70 \mathrm{~B}$ & $<0.70 \mathrm{~B}$ & $<0.70 \mathrm{~B}$ \\
\hline 0.1761 & PT & $<0.70 \mathrm{~B}$ & $<0.70 \mathrm{~B}$ & $<0.70 \mathrm{~B}$ & $<0.70 \mathrm{~B}$ & $<0.70 \mathrm{~B}$ & $0.73 \mathrm{AB}$ \\
\hline
\end{tabular}

${ }^{a}$ Adjacent site was an area on the dorsal surface adjacent to the inoculation site. Inoculated side was the entire dorsal surface.

${ }^{b}$ High-inoculum level $=$ approximately $4.8 \log _{10} \mathrm{CFU} / \mathrm{cm}^{2}$.

${ }^{c}$ Low inoculum level $=$ approximately $2.5 \log _{10} \mathrm{CFU} / \mathrm{cm}^{2}$.

${ }^{d}$ Cap on is the Beef Loin, Top Sirloin Butt, Boneless (IMPS 184) and cap off is the Beef Loin, Top Sirloin Butt, Center Cut, Boneless, Cap Off (IMPS 184B).

$e$ Top sirloin butts were stored under refrigeration $\left(2^{\circ} \mathrm{C}\right)$ for either 0,14 or 28 days.

${ }^{f}$ Initial refers to counts before treatment was applied. Water wash (WW) refers to washing the entire exterior surface with tap water. Full trim (FT) removed all exterior surfaces. Partial trim (PT) removed only the dorsal surface.

${ }^{g}$ Numbers within columns within inoculation levels with different letters significantly differ $(P<0.05)$.

${ }^{h}$ Detection limit $=0.7 \log _{10} \mathrm{CFU} / \mathrm{cm}^{2}$ 
TABLE 3. Least squares means for storage day $\times$ cap $\times$ treatment effect on counts $\left(\log _{10} \mathrm{CFU}_{\mathrm{cm}}{ }^{2}\right)$ of $\mathrm{E}$. coli O157:H7 at the opposite side ${ }^{a}$ of top sirloin butts

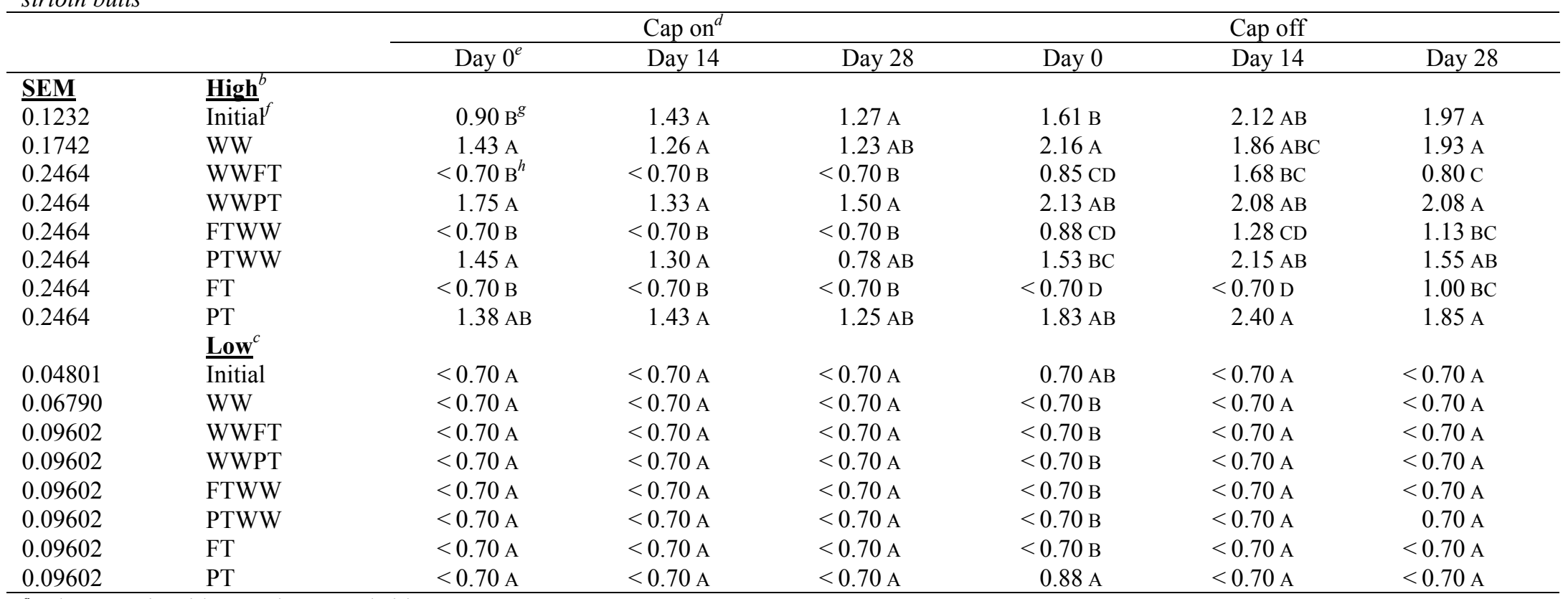

a The opposite side was the ventral side.

${ }^{b}$ High-inoculum level $=$ approximately $4.8 \log _{10} \mathrm{CFU} / \mathrm{cm}^{2}$.

${ }^{c}$ Low inoculum level $=$ approximately $2.5 \log _{10} \mathrm{CFU} / \mathrm{cm}^{2}$.

${ }^{d}$ Cap on is the Beef Loin, Top Sirloin Butt, Boneless (IMPS 184) and cap off is the Beef Loin, Top Sirloin Butt, Center Cut, Boneless, Cap Off (IMPS 184B).

${ }^{e}$ Top sirloin butts were stored under refrigeration $\left(2^{\circ} \mathrm{C}\right)$ for either 0,14 or 28 days.

${ }^{f}$ Initial refers to counts before treatment was applied. Water wash (WW) refers to washing the entire exterior surface with tap water. Full trim (FT)

removed all exterior surfaces. Partial trim (PT) removed only the dorsal surface.

${ }^{g}$ Numbers within columns within inoculation levels with different letters significantly differ $(P<0.05)$

${ }^{h}$ Detection limit $=0.7 \log _{10} \mathrm{CFU} / \mathrm{cm}^{2}$ 


\section{VITA}

\begin{tabular}{|c|c|}
\hline Name: & Jacob Lynn Lemmons \\
\hline Address: & $\begin{array}{l}\text { Department of Animal Science } \\
2471 \text { TAMU } \\
\text { College Station, TX } 77843\end{array}$ \\
\hline Email Address: & JLL05@tamu.edu \\
\hline Education: & $\begin{array}{l}\text { Texas A\&M University } \\
\text { B.S., Animal Science } \\
\text { May } 2009\end{array}$ \\
\hline & $\begin{array}{l}\text { Texas A\&M University } \\
\text { M.S., Animal Science (Meat Science) } \\
\text { May } 2011\end{array}$ \\
\hline
\end{tabular}

